\title{
On the Internationalisation and Harmonisation of Archival Law
}

\author{
Herbjørn Andresen \\ Associate Professor, Faculty of Social Sciences, Department of Archivistics, \\ Library and Information Science, OsloMet - Oslo Metropolitan University \\ herbjorn.andresen@oslomet.no
}

\begin{abstract}
Archival laws exist in most countries, with some similarities due to a common professional basis. Over several decades, regional and global laws have evolved in different fields imposing requirements, or expectations, for reliable and accessible archives. Merely a few attempts have been made to harmonise archival law in the sense of pursuing a goal of rule similarity. Still, there seems to be an increase of areas where international law or regional harmonisation of laws presupposes archival law with a capacity to safeguard creation and preservation of reliable archives, documenting government activities. Even without manifest goals of harmonising archival law into uniform rules, the broad range of emerging requirements on reliable archives may lead to some form of approximation of archival law. Following a broad account of developments in this field, Sections 2 through 4, there is a discussion of advantages and disadvantages of stronger or weaker modes of harmonisation. Strong harmonisation could perhaps more convincingly safeguard the reliability of archives, at the cost of a possible lock-in of the scope of archival law. Weaker forms of harmonisation yield more differentiated archival laws. On the other hand, weak harmonisation may be more adaptive to developments in adjacent fields.
\end{abstract}

\section{Keywords}

archives - internationalisation - harmonisation 


\section{Introduction}

Archival law concerns authorities and institutions responsible for archival materials, as well as the collections of such materials that these institutions preserve. Definitions of the term 'archives' itself often cover two related meanings, referring both to collections of records and to institutions in charge of them. ${ }^{1}$ Perhaps needless to say, modern conceptions of archives include digital materials as well, and institutions capable of managing them. Although digital materials are a natural part of the archival field, digital data is seldom mentioned in high level archival law. This can in part be explained by the age of such laws. A modest example is the recent Icelandic law, which quite briefly mention it as part of the National Archives responsibilities to lay down rules on the preparation and transfer of records and data archives. ${ }^{2}$ An archival collection originates from records that document various transactions, and it usually refers to records that are no longer in current use. The capacity for providing evidence of transactions is of paramount importance both for current records and for non-current archival collections. Archival law includes mandates and measures for maintaining the evidential value and accessibility over time.

Although archival laws are mainly an object for national legislation, some elements of internationalisation of archival law have been evolving over the last decades. The emerging internationalisation seems to be of a composed nature, involving a supranational need to protect cultural heritage, to make decisions on which country owns specific materials in situations of conflict, and to fulfil individuals' right to know the truth. In addition to these driving forces, archival law also seems to be increasingly intertwined into data protection law, which may bring about a more uniform view on archival law as a side effect. This article discusses internationalisation of archival laws from a bird'seye view, within the scope of The United Nations (UN), The Council of Europe (CoE), and The European Union (EU).

The internationalisation of archival law includes elements of both professional standardisation and legal harmonisation. Harmonisation is itself a complex concept, which might comprise different goals, or ambitions, both for the 'sameness' of rules and for their application or enforcement, as well as different forums and methods. Although harmonisation as such is a legislative endeavour, it often builds on and presupposes approximation of cultural and administrative traditions as well.

1 See for example the definition in Council of Europe (CoE), 'Recommendation No. R (2000) 13 of the Committee of Ministers to Member States on a European Policy on Access to Archives'. Retrieved 18 October 2019, https://rm.coe.int/16804cea4f.

2 Public Archives Act, 2014 No 77, 28 May, Art. 8(2). Retrieved 18 October 2019, https://skjala safn.is/files/docs/ThePublicArchivesAct-in-Iceland-No-77-2014.pdf. 
Further, a distinction can be drawn between consequential and procedural harmonisation. ${ }^{3}$ Consequential is about what extent of harmonisation is achieved, while procedural is about the means and methods applied. Harmonisation is intentional, but not necessarily aiming for a binding set of common rules. In this broad sense, the concept of harmonisation may provide an analytical approach to these evolving contact points, similarities, and common views amounting to an internationalised concept of archival law. To serve the purpose of this article, different combinations of goals, forums, intended results and methods are referred to as different modes of harmonisation.

There are several weighty reasons for harmonising archival law. Some of these reasons primarily become relevant in situations of low political stability. The right to judicial remedy, measures to combat impunity, and the protection of cultural heritage are themselves important reasons to maintain reliable archives. However, these reasons do not necessarily call for harmonisation of archival law between countries with stable borders, a legitimate political regime, and a functioning legal and administrative system. The benefit of harmonisation would merely be to provide precautions for possible future situations of political instability. On the other hand, there are also reasons for harmonisation of archival law that mostly apply to benevolent relationships between stable countries. The value of archives, for purposes of research and dissemination, may increase by lowering the legal and practical thresholds for use across borders. Restrictions on use of archives are also in part subject to border-crossing rules and regulations, where some extent of harmonisation is already in place, for instance on personal data protection and on intellectual property rights. The interplay between archival law and other fields of law that are subject to more pervasive modes of harmonisation, could also influence the consequential harmonisation of archival law, whether intentionally or as an unintended side effect.

An archival law now exists in most countries. Over several decades, International Council on Archives (ICA) compiled information on archival laws around the world. ${ }^{4}$ In their last comprehensive report on archival laws, finalised in 1994, they had collected information on archival laws in almost 140 countries that still exist. The number of countries with an archival law is now

3 M. Andenas, C. Baasch Andersen and R. Ascroft, "Towards a theory of harmonisation", in: M. Andenas and C. Baasch Andersen (eds.), Theory and Practice of Harmonisation (Cheltenham: Edward Elgar Publishing, 2011) pp. 572-594.

4 Index pages of Archivum XLI [vol. 41] (1996) pp. XV-XXII. Note: Archivum was an annual journal published by International Council on Archives from 1951 to 2000. Eight issues of Archivum, the first one in 1962, were dedicated to archival laws in all corners of the world. Volume XLI includes a comprehensive index of every country that had been included in a review of archival laws in one or more issues of Archivum. 
slightly higher. A few more countries, mainly ex-Soviet and ex-Yugoslavian, have passed archival legislation later than 1994. However, an even more important feature than the number of countries, in the context of harmonisation, was ICA's set of criteria for what subjects an archival law were supposed to cover. The criteria included legal definition of archives, legal protection for archives, a government entity responsible for application of the archival law, organisation of public archival institutions, professional training of archivists, control and management of current records, preservation measures, access rules, and provisions for special categories of archives or types of records. ${ }^{5} \mathrm{Ar}-$ chival laws, that match these criteria, are not necessarily contained within the same statute or legislative act. For instance, in Norway the general Freedom of Information Act mainly governs access to archives. ${ }^{6}$ There are some special provisions for access in other legislation as well, but none in the Norwegian Public Archives Act. ${ }^{7}$ Furthermore, most countries do not fulfil every criterion drawn up by ICA for identification of archival laws. For instance, there are no legal requirements for professional training of archivists in Norway. Archival law in different countries share some important features, but both their structure and their actual provisions are quite different in many respects. ${ }^{8}$

The consecutive chapters of this article give an account of different modes of harmonisation and international developments of archival law. Following these chapters, there is a discussion on whether the different modes imply a more wide-ranging aggregate harmonisation, or if they imply competing views on what archival law ought to be.

\subsection{Introduction to Archives as Cultural Heritage}

Archives as cultural heritage is an aspect of why archives are kept and maintained, beyond the immediate retrieval and reuse of records, to evidence a past event or for some other specific purpose. Cultural heritage is about identity

5 A. Vanrie, 'Introduction' Archivum XLI (1996) p. XI. Note: The list of criteria is paraphrased here, for the sake of brevity.

6 Act no. 2006-06-19-16, 'Act relating to the right of access to documents held by public authorities and public undertakings (Freedom of Information Act)'. Retrieved 18 October 2019, https://lovdata.no/dokument/NLE/lov/2006-05-19-16.

7 Lov 1992-12-04-126 om arkiv. Note: This Norwegian act is usually referred to as 'The Public Archives Act' when it is mentioned in English texts, but no official or semi-official translation of the complete act exists.

8 A. Vanrie, supra note 5, pp. XI-XIII gives an account, which is an expressed oversimplification, of some general trends in the development of archival law internationally. 
and connectedness, and it covers different manifestations, such as archives, museum collections and historical sites, and even intangible heritage such as oral traditions or rituals. In a sense, archives as cultural heritage could be rephrased archives as part of the cultural heritage. Protection of cultural heritage is one of the main functions of the UN organisation UNESCO. The preamble of the 1954 Hague convention states UNESCO's view of cultural heritage as a common good and a shared responsibility: '[D]amage to cultural property belonging to any people whatsoever means damage to the cultural heritage of all mankind, since each people makes its contribution to the culture of the world' 9 The field of cultural heritage comprise different modes of harmonisation, as described in this chapter.

\subsection{Archives at Risk, Protection of Cultural Heritage}

UNESCO engages in protecting cultural heritage by way of different activities and initiatives, to identify and secure proper conservation of important cultural sites and objects. The instrument for protection of cultural heritage that is the most pertinent to the question of harmonisation of archival law is the 1954 Hague convention. ${ }^{10}$ A noticeable visual feature of the convention is the 'blue shield' emblem, mentioned in Articles 16 and 17, for identification of cultural property under special protection. Article 1(a) identifies archives as one out of many types of cultural property. The 1954 convention imposed a duty on contracting parties both to respect cultural property within their own or foreign territory, as well as to safeguard cultural property within their own territory against foreseeable effects of an armed conflict. However, the 1954 convention made no explicit call for measures in national legislation to achieve the goals of the convention.

Armed conflicts have continued to cause damage to cultural heritage, revealing a need for more effective protection. In 1999, a second protocol to the convention was adopted. Among other measures, the second protocol introduced the need for adequate domestic legal and administrative measures as one of the necessary conditions for the enhanced protection measures covered by the convention. ${ }^{11}$ The second protocol also established a committee, composed of

Unesco, 2010. 'The 1954 Hague Convention for the Protection of Cultural Property in the Event of Armed Conflict and its two (1954 and 1999) Protocols: Basic Texts (UNESCO, Paris 2010)'. Retrieved 18 October 2019, https://unesdoc.unesco.org/ark:/48223/pfoooo187580. Note: Quoted from preamble to the 1954 convention.

10 Ibid.

11 Ibid, Second Protocol, Article 1o(b). 
twelve parties to the convention. One of the committee's functions is to develop guidelines for the implementation of the second protocol. ${ }^{12}$ The committee issued a comprehensive guideline in 2009, covering inter alia criteria for sufficient domestic legislation to come under the enhanced protection. ${ }^{13}$

\subsection{The UNEsco Draft Model Law on Archives, and Subsequent Harmonising Efforts}

A model law is drafted code, which is open for adoption by countries. There can be varying degrees of formalising the adherence to a model law. Still, the nature of a model law is that it serves as a guide for national legislation. The advantage of a model law is 'that it provides a more flexible approach to the process of harmonisation because States can adopt the model law as the basis for their own legislation, but they are not bound to the specific provisions. ${ }^{14}$ However, the flexibility of a model law also entails a more modest degree of harmonisation compared to binding treaties or conventions.

Building on ICA's early contributions in mapping archival laws, there were concerns about the ability of many countries to provide for robust and reliable archiving institutions and practices. Inadequate measures for safeguarding archives turned out to be a problem also in times of peace, especially in countries with less developed legal systems. An initiative by UNESCO was to communicate knowledge about the needs and principles for archival legislation in the form of a model law. They assigned the task of drafting a model law to ICA. The resulting document was 'a draft law on archives which would be suitable for countries at varying stages of development', issued in $1972 .{ }^{15}$ The model law comprised tasks and competences for national archival authorities and institutions, along with quite detailed prescriptions on the acquisition, curation, protection, preservation and dissemination of archival materials. The draft model law consists of 237 articles, many of them with a copious wording.

The draft model law did not turn out to be very useful as a practical tool for propagating archival law. In 1985, UNESCO issued a guidance document, discussing and recommending various legislative solutions to fundamental

\footnotetext{
12 Ibid, Second Protocol, Articles 24(1) and 27(1)(a).

13 Ibid, The Guidelines, paras. 39 and 40.

14 S. Eiselen, "Globalization and Harmonization of International Trade Law", in: M. Faure and A. van der Walt (eds.), Globalization and Private Law: The Way Forward (Cheltenham: Edward Elgar Publishing 2010) pp. 97-136, at p. 112.

15 S. Carbone and R. Guêze, Draft model law on archives: description and text (UNEsco, Paris 1972).
} 
principal questions concerning archives. ${ }^{16}$ The discussions in the 1985 guidance considered different provisions that were already in place in archival laws in a large number of countries in different parts of the world. The 1985 guidance cited a critique to the 1972 model law, stating that although it had been a 'further contribution towards harmonizing archival legislation', it was also 'too closely based on Latin, especially Italian, archival legislation to be of direct value to countries with a different experience. ${ }^{17}$ Hence, the 1985 guidance may have strengthened the agreement on what basic issues archival laws ought to cover, at the cost of a diminished similarity of rules compared to the ambition of the 1972 draft model law.

Harmonising archival law may be even more difficult for rules on private documents held in public archives. The 1972 draft model law suggested quite interventionist rules on acquisition of valuable private archives, and to impose certain constraints if the archive was still in custody of the owner. This somewhat optimistic view on the possibility for harmonised rules on private archives was toned down in the 1985 guidelines: "The tendency in current legislation is to impose some control by the archival authorities on private archives, at least on those which are of main general interest. The extent to which this control can be effected will vary from country to country. A too rigid control apart from its feasibility - may lead to concealment and even destruction of private archives.18

Also, worth noting, UNESCO adopted a charter on digital cultural heritage in $2003 .{ }^{19}$ This charter is not limited to archives; it is equally relevant to other document-based cultural heritage, such as library materials. The prevalent international framework standard for digital archiving, preservation and dissemination, the OAIS reference model, embraces an even wider perspective on the commonalities of the problems all digital materials face over time. ${ }^{20}$ The problems pertaining to digital materials are in part similar to, and in part different from, maintaining physical documents. The charter phrases the problem this way: 'The world's digital heritage is at risk of being lost to posterity. Contributing

16 E. Ketelaar, Archival and records management legislation and regulations: a ramp study with guidelines (UNESCO Paris 1985).

17 Ibid, pp. $1-2$.

18 Ibid, p. 23.

19 Unesco Charter on the Preservation of Digital Heritage (2003) Records of the General Conference (Volume 1 Resolutions) 74. Retrieved 18 October 2019, https://unesdoc.unesco .org/ark:/48223/pfoooo133171.

20 ISO 14721:2012, 'Space data and information transfer systems - Open archival information system (OAIS) - Reference model' (Geneva: International Organization for Standardization, 2012). 
factors include the rapid obsolescence of the hardware and software which brings it to life, uncertainties about resources, responsibility and methods for maintenance and preservation, and the lack of supportive legislation.21 The charter further points out the role of UNESCO in preservation of digital heritage, which is, inter alia, to 'foster co-operation, awareness-raising and capacitybuilding, and propose standard ethical, legal and technical guidelines, to support the preservation of the digital heritage. ${ }^{22}$ So far, the follow-up activities pertaining to the charter on digital cultural heritage has predominantly been about monitoring, comparing policies and exchange of subject-matter knowledge, and to a lesser extent about legislative measures. ${ }^{23}$

\subsection{European Union Co-operation on Archives as Cultural Heritage}

The EU treaties literally restrain the harmonisation of laws in the field of cultural heritage. As stated in the Treaty on the Functioning of the European Union, 'the European Parliament and the Council ... shall adopt incentive measures, excluding any harmonisation of the laws and regulations of the Member States. ${ }^{24}$ The mode of harmonisation is limited to softer policy instruments in certain areas, including the cultural field, where ' $[t]$ he Union shall have competence to carry out actions to support, co-ordinate or supplement the actions of the Member States. ${ }^{25}$ There is also a further constraint on the harmonisation of cultural heritage legislation in the EU; the general prohibition on quantitative restrictions on imports and exports between Member States has some exceptions, one of those exceptions is protection of national artistic, historic or archaeological value. ${ }^{26}$

Kept within these limits imposed by the treaties, the EU enacted recommendation 2005/835/EC on 'actions to increase co-operation in the field of archives in Europe'. ${ }^{27}$ This recommendation established The European Archives Group (EAG), consisting of experts designated by the Member States and the institutions of the Union. The main task of the EAG is to ensure co-operation and co-ordination on general matters related to archives. The measures include

\footnotetext{
21 UNESCO 2003 supra note 19, Article 3, first clause.

22 Ibid, Article 12(c).

23 The follow-up activities are chiefly available at the online resource UNESCO PERSIST Programme. Retrieved 18 October 2019, https://unescopersist.com/.

24 Treaty on the Functioning of the European Union (TFEU), (consolidated version 7.6.2016) OJ C 2016 202/1, Article 167(5) (emphasis added).

25 TFEU Article 6(c).

26 TFEU Article 36, cf. Arts. 34 and 35 .

27 EU Council Recommendation of 14 November 2005 on priority actions to increase cooperation in the field of archives in Europe, 2005/835/EC, OJ L 2005 312/55.
} 
both the protection of archival collections and the propagation of standards for records creation and management. One of the measures stated in the recommendation is to promote best practice for archival law and related legislation. To this end, the national archives of the Member States should 'monitor new draft legislation in that field to be enacted in any of the Member States, with the aim of identifying best practices. ${ }^{28}$

With that, the EU does not harmonise archival law as a means of protecting cultural heritage in any direct sense. The recommendation 2005/835/EC implies a softer mode of harmonisation than directives or regulations would provide. However, the EAG may exert an influential power in pointing out archives-related consequences of other EU legislation that are subject to more direct modes of harmonisation.

\section{$3 \quad$ Regime Changes and Transitions}

\subsection{Introduction to Archives in Regime Changes and Transitions}

In situations of post-conflict regime changes or transitions, archives often become both an important, and a difficult, issue to resolve. In most such situations, the risks of destruction or looting will be less pressing than in an ongoing war. However, there can be legitimate administrative needs for historical records on both sides of a ceased conflict. Beyond the immediate succession of administrative activities, control of archives may be part of forming the nations' self-images in the aftermath. Ownership of the archives is a recurring question in international law. The decisions on who controls the archives is also considerably important for examining injustices done to, or by, individuals. Control of the archives affects access to, and consequently interpretations of, individuals' history. In international law, some principles and guidelines have been formed both on the levels of States and of individuals, but no binding multilateral rules are in place.

\subsection{State Succession}

On the clock of history, State borders and political regimes are mutable. Breakup of unions, secessions of colonies, the end of oppressive regimes, and unfortunately sometimes reintroduction of authoritarianism, have taken place in all corners of the world over the last couple of centuries. To various degrees, the archives have, along with other State property, been objects of dispute.

28 Ibid, clause $\mathrm{B}(4)$. 
Ownership and access to archives in situations of State succession is an old problem of international law. The case of Norway's secession from Denmark in 1814 demonstrates the problem. Even though the Treaty of Kiel, in 1814, ordered transferral of necessary archives from Denmark to Norway, there were lengthy negotiations on what archives to transfer. Different parts of the archives were agreed on and transferred decades apart. The final settling agreement was reach as late as the year 2000, almost 200 years after the secession. ${ }^{29}$

On the event of secession, the archives often hold records of both administrative and cultural value for all the involved nations. The duality of archives, both as vehicles of administrative continuity and as cultural property, adds to the difficulty of deciding their future ownership. Some principles of customary international law have emerged, emphasising where the archives are needed, both for the functioning of the new State and for the status of the territory where the archive actually is located. ${ }^{30}$

No multilateral treaties are in place for resolving ownership of archives in the event of State succession. In the early 1980s, there were major efforts at the UN to achieve a binding treaty regulating, inter alia, archives in the event of State succession. At a conference held in Vienna in 1983, The 'Vienna Convention on Succession of States in respect of State Property, Archives and Debts' was adopted. ${ }^{31}$ According to the principles outlined in the articles pertaining to archives in the Vienna convention, the territorial pertinence and administrative needs of the successor State would prevail. ${ }^{32}$ However, the convention failed to gain sufficient support, and never entered into force. The convention was turned down mainly by Western countries. There have been different analyses of why it failed, some emphasising a counter reaction to the rise in

29 Å. Svendsen, Arkivet. En beretning om det norske riksarkivet 1817-2017 (Oslo: Press forlag, 2017) p. 427. Note: 20oth anniversary history book on The National Archives of Norway 1817-2017.

30 There is a rich literature on the development of international law in this field, contributed by authors with a background both in the archival community and in international law. See for example G. Mackenzie, "From Solferino to Sarajevo: Armed Conflict, International Law, and Archives", in: M. Procter, M. Cook and C. Williams (eds.), Political Pressure and the Archival Record (Society of American Archivists, 2005) pp. 239-257; D. Cox, "Archives \& Records in Armed Conflict: International Law and the Current Debate Over Iraqi Records and Archives", Catholic University Law Review 59(4) (2010); C. Kecskeméti, "Archives Seizures: The Evolution of International Law", in: J. Lowry (ed.), Displaced Archives (New York: Routledge, 2017) pp. 12-20.

31 UN 'Vienna Convention on Succession of States in respect of State Property, Archives and Debts' (1983 - Not yet in force) UNTC A/CONF.117/14, available at https://treaties.un.org/ doc/source/docs/a_conf_117_14-E.pdf. Retrieved 18 October 2019.

32 A. Jakubowski, State Succession in Cultural Property (Oxford University Press, 2015) pp. $171-172$. 
codification of international law, and some emphasising conflicting political interests in the matter of reversing the colonial legacy. ${ }^{33}$

\subsection{Archives as a Safeguard against Impunity}

On the level of individuals, access to archives is a precondition for fulfilling the right to know the truth, and the right to reparation. According to the Universal declaration of human rights, '[e]veryone has the right to an effective remedy by the competent national tribunals for acts violating the fundamental rights granted him by the constitution or by law' ${ }^{34}$ Implementing this right into national law also entails a need for safeguards against impunity, 'if governments in good faith implement the human rights standards, they have to ensure criminal responsibility for those who deliberately violate the rights. ${ }^{35}$ Safeguards against impunity 'would comprise principles related to the right to know what took place when the violations occurred.36 Thus, a duty for States to keep archives is to some degree embedded in the right to an effective remedy.

In the 199os, the UN Commission on Human Rights initiated a study on the impunity of perpetrators of human rights. The result of this study was a report issued by Special Rapporteur Louis Joinet, presenting a set of principles pertaining to victims' legal rights, as a broad strategic framework for action against impunity. ${ }^{37}$ The Joinet principles were subdivided into three categories: (a) The victims' right to know; (b) the victims' right to justice; and (c) the victims' right to reparations. The report's clause no. 17 states firstly that the right to know is both an individual and a collective right, and secondly that the corollary of this right is a 'duty to remember', which the State must assume. Clause no. 25 states that ' $[\mathrm{t}]$ he right to know implies that archives must be preserved, especially during a period of transition', further elaborated in a few suggested protective measures. ${ }^{38}$

An important part of the background for linking a 'right to know the truth' to the campaign against impunity, also referred to in the Joinet report, was the decisions and reporting from the regional UN human rights body of Latin

33 Ibid, p. 168. See also A. Sarvarian, "Codifying the Law of State Succession: A Futile Endeavour?", European Journal of International Law (EJIL) 27(3) (2016) 789-812.

34 UDHR Article 8.

35 A. Eide, "Preventing Impunity for the Violator and Ensuring Remedies for the Victim", Nordic Journal of International Law (NJIL), 69(1) (2000) 1-10, at p. 4.

36 Ibid, p. 7.

37 UNCHR 'Question of the impunity of perpetrators of human rights violations (civil and political). Revised final report prepared by Mr. Joinet pursuant to Sub-Commission decision 1996/119' (1997) UN Doc E/CN.4/Sub.2/1997/20/Rev.1. Retrieved 18 October 2019, http://undocs.org/en/E/CN.4/Sub.2/1997/20/Rev.1.

Ibid. 
America. ${ }^{39}$ In their annual report 1985-1986, The Inter-American commission on human rights stated that ' $[\mathrm{e}]$ very society has the inalienable right to know the truth about past events. ${ }^{40}$ A similar wording is used in Joinet's principle no. 1, that bears the heading 'The inalienable right to the truth'. The duty to remember is principle no. $2 .{ }^{41}$

A few years later, the Commission on Human Rights requested the SecretaryGeneral to appoint an independent expert to update The Joinet principles '... to reflect recent developments in international law and practice, including international jurisprudence and State practice.42 The revised principles, known as The Orentlicher principles, offer some accentuations on the topic of archives and the duty to preserve memory. ${ }^{43}$ Some of the revisions pertaining to archives is the clarification of 'documents' as a broad range of formats including various types of electronic records, the need for facilitating access based on professional archival practice, and the need for safeguarding privacy without impeding the right to know and without imposing censorship. ${ }^{44}$ Another further development from The Joinet principles is an emphasis on truth commissions that may develop their own archives arising from their work in particular instances of transitional justice. This part of the archiving practices does not appear to be immediately relevant to the States' duty to preserve memory. ${ }^{45}$

39 For an account of the background for 'the right to truth' see J.E. Méndez, "An emerging "right to truth": Latin-American contributions", in: S. Karstedt (ed.), Legal institutions and collective memories (Oxford: Hart Publishing, 2009) pp. 39-6o.

40 Annual report of The Inter-American commission on human rights 1985-1986, Chapter v. Retrieved 18 October 2019, https://www.cidh.oas.org/annualrep/85.86eng/chap.5.htm.

41 Joinet report, supra note 37.

42 UNCHR Resolution 2004/72. Retrieved 18 October 2019, http://www.refworld.org/ docid/43f313869.html.

43 UNCHR 'Impunity: Report of the Independent Expert to Update the Set of Principles to Combat Impunity, Diane Orentlicher' (2005) UN Doc E/CN.4/2005/102. Retrieved 18 October 2019, http://undocs.org/en/E/CN.4/2005/102. Note: The report explained the background for the revised principles. The principles themselves were issued as a separate document: UNCHR 'Addendum [to E/CN.4/2005/102] Updated Set of principles for the protection and promotion of human rights through action to combat impunity' (2005) UN Doc E/CN.4/2005/102/Add.1. Retrieved 18 October 2019, http://undocs.org/en/E/ CN.4/2005/102/Add.1.

44 Ibid.

45 For a comprehensive account of the creation of archival materials in the work of truth commissions, see T. Huskamp Peterson, "Archives for justice, archives of justice", in: J.B. Gardner and P. Hamilton (eds.), The Oxford Handbook of Public History (Oxford University Press, 2017) pp. 163-177. 
The Commission on Human Rights endorsed The Orentlicher principles, 'as a guideline to assist States in developing effective measures for combating impunity' in a subsequent resolution. ${ }^{46}$ The principles have been, and are still, influential in the combat against impunity discourse. However, it is worth noting they are not legal rights to be invoked. Neither the Commission, its successor the Human Rights Council, nor the General Assembly has formally adopted the principles. According to a commentary on the principles to combat impunity, it is 'a widely held view [that] the Principles are best seen as flexible instrument of guidance with the potential to gradually acquire, through widespread usage, quasi-legal recognition: ${ }^{37}$

The regional legal development in Europe has adopted a similar conception of a right to know the truth. For instance, in a resolution by The Parliamentary Assembly of the Council (PACE), they endorse various Human Rights bodies' contributions to the emerging legal framework against impunity. ${ }^{48}$ However, unlike the Joinet-Orentlicher principles, the PACE resolution does not explicitly include a duty to preserve archives on its list of proposed safeguards against impunity. The European Court of Human Rights (ECtHR) has also emphasised the right of victims, and their families, to know the truth about violations of the right to life. ${ }^{49}$ Although the ECtHR assumed a right to truth in this case, they did not make any explicit claim that it implies a duty for States to preserve archives.

The EU, as a part of their action plan on human rights and democracy, issued a policy framework on transitional justice. ${ }^{50}$ The objective is to enable the EU to play a more active and consistent role in regional transitional justice processes. The perspectives and measures are largely based on the JoinetOrentlicher principles, inter alia, The EU recommendation 'encourages states to implement truth commissions' and to 'preserve memory by undertaking measures such as securing archives and other evidence.'51

46 UNCHR Resolution 2005/81. Retrieved 18 October 2019, http://www.refworld.org/docid/ 45377c93o.html.

47 F. Haldemann and T. Unger, "Introduction", in: F. Haldemann and T. Unger (eds.), The United Nations Principles to Combat Impunity. A commentary (Oxford University Press, 2018) pp. 4-25.

48 PACE Resolution 1463 (2005). Retrieved 18 October 2019, http://assembly.coe.int/nw/xml/ XRef/Xref-XML2HTML-en.asp?fileid=17371.

49 e.g., ECtHR Association "21 December 1989" and Others v Romania, nos 33810/07 and 18817/08, § 144, 24 May 2011.

50 Council of the European Union, 'The EU's Policy Framework on support to transitional justice', 13576/15 (16 November 2015). Retrieved 18 October 2019, http://data.consilium.europa.eu/doc/document/ST-13576-2015-INIT/en/pdf.

$5^{1} \quad$ Ibid, p. 18. 


\section{Rules on Use, Access and Restrictions}

\subsection{Introduction to Use, Access and Restrictions}

The most obvious reason for keeping and preserving archives is to enable future use of its materials. Access to archives may refer both to fulfilling individuals' rights as directly affected by the records, and access to information of public interest. In this context, the focus is on access for the public interest. Workable conditions for future use of course play an important part in protecting archives through political instability. Some degree of harmonised rules on access and use is also viewed with favour between co-operating countries under politically stable and benevolent circumstances. However, harmonised rules on access and use entail a need for harmonisation of the restrictions on access and use as well.

There is a small, yet important, distinction between access and use, both as legal concepts and in archival theory. To the professional archivist, access is an obligation to enable use of the archives, conforming to restrictions that may apply. Providing access does not entail control of the interpretation, it is a service to be offered in a neutral fashion. The distinction between access and use is explained this way in an article on archival theory: 'Access is not the actual use of archives. ... The users themselves are responsible for the content, that they find in the records. 52 Thus, a legal right to access means access to raw materials for backing claims, beliefs or interpretations. An access right naturally implies a right to use the information for purposes of pursuing basic individual rights. Other uses of accessible information may be subject to needs for an independent legal basis, even for a person who has a right to access it.

As a general notion, a right to information access is part of European law by way of freedom of information, as a corollary to the freedom of expression. ${ }^{53}$ A right to access to archives has been the subject of a recommendation made by the Council of Europe; otherwise, it is mainly regulated by national laws. Compared with access rights, provisions on the use of archives is to a noticeably larger extent part of internationalised law. In particular, data protection legislation is a field that widely affects the use of archives. Secondary, the EU directive on reuse of public sector information promotes use of information in archives as well as other sources. A third strand of internationalised law that is pertinent to the use of information is intellectual property rights. Archiving does not imply acquisition of rights, nor a general right for

\footnotetext{
52 A. Menne-Haritz, "Access - the reformulation of an archival paradigm", Archival Science $1(1)(2001) 57-82$. 
the archiving institution to disseminate the work. Some legal exemptions exist, which are partly subject to harmonisation efforts.

\subsection{Council of Europe Recommendation on a European Policy on Access to Archives}

In the 1990s, the changing regimes in the Eastern Europe led to an increased number of Member States in the CoE. The CoE issued a recommendation on access to archives in 2000, invoking Articles 8 and $10 \mathrm{ECHR}$, along with the Data protection convention ETS No. $108 .{ }^{54}$ The preamble of the recommendation raises, along with a series of positive affirmations on the cultural and individual value of access to archives, a concern about 'the complexity of problems concerning access to archives at both national and international level due to the variety of constitutional and legal frameworks, of conflicting requirements of transparency and secrecy, of protection of privacy and access to historical information, all of which are perceived differently by public opinion in each country'.55 The recommendation statement is a call for CoE Member States to adopt legislation on access to archives, in line with principles outlined in the appendix to the recommendation. The core of the principles is, paraphrased, that national legislation should provide for open public archives, requiring a legal base for restrictions to access, or for exceptions to a general closure period. ${ }^{56}$

Compared to the EU, CoE takes a different approach to harmonisation of archival law in two respects. The most obvious one is the call made by $\mathrm{CoE}$ for national legislation on access to archives in line with specified principles, while the EU keeps archival legislation out of their harmonisation efforts. A little less obvious, perhaps, is that the EU in their arenas for co-operation in the field of archives, conflate the domains of archives and of current records. ${ }^{57}$ CoE has issued separate recommendations on access to archives and on access to official documents. ${ }^{58}$ The scope of the latter is comparable to freedom of information acts in many countries. On the matter of access to current, official documents, $\mathrm{CoE}$ has also prepared a treaty text, aiming to be a binding convention laying out minimum requirements for national legislation on access to

\footnotetext{
54 CoE R (2000) 13, supra note 1.

55 Ibid.

56 Ibid, appendix to the recommendation, especially clause 7-7.2.

$572005 / 835 / \mathrm{EC}$, supra note 27.

$58 \mathrm{CoE}$ 'Recommendation $\operatorname{Rec}(\mathbf{2 0 0 2}) 2$ of the Committee of Ministers to Member States on Access to Official Documents'. Retrieved 18 October 2019, https://rm.coe.int/ogoooo 16804 c6fcc.
} 
official documents. ${ }^{59}$ The treaty has been open for signature by Member States since June 2009, but has still not gained enough ratifications to enter into force.

\subsection{Archives and Fair Processing of Personal Data}

Current data protection law in EU is the General Data Protection Regulation (GDPR), which is a detailed and far-reaching harmonised set of rules and enforcement mechanisms for processing of personal data. ${ }^{60}$ Though the harmonising force of the GDPR is more pervasive than that of its predecessors, the provisions most relevant to striking the balance between fair processing of personal data and archiving purposes build on data protection principles developed as harmonisation efforts from the beginning of the 1980s.

The European convention on human rights, which entered into force in 1953, recognises a right to respect for private and family life. Interference with this right, from public authorities, must both be prescribed by law, and necessary in a democratic society. ${ }^{61}$ From the outset, archiving was not perceived as possibly being at odds with a right to privacy. The subsequent development of information technology, causing digital data about individuals to be collected, stored and dispersed significantly wider and faster than before, raised concerns about the transparency and controllability of the emerging new technologies. Protecting privacy in a digital age called for more targeted legislation. Data protection laws were developed in some countries in the 1970s, in the face of a multi-national law-and-technology discourse. The prospects of increasing transnational exchange of data gave rise to the quest for common principles to guide national legislation on personal data.

In 1980, the Organisation for Economic Co-operation and Development (OECD) issued 'Guidelines on protection of privacy and transborder flow of personal data. ${ }^{62}$ The mission of OECD is to foster economic growth and international trade. They analyse and make recommendations on many issues, but it is not a legislative body in any usual sense. OECD is a transcontinental organisation; its members are fairly wealthy countries. By 1980, when these guidelines

59 CoE, 'Council of Europe Convention on Access to Official Documents' (2009). Retrieved 18 October 2019, https://www.coe.int/en/web/conventions/full-list/-/conventions/treaty/ 205 .

6o EP and Council Regulation on the protection of natural persons with regard to the processing of personal data and on the free movement of such data, and repealing Directive 95/46/EC (General Data Protection Regulation), (EU) 2016/679, OJ L 2016 119/1.

$61 \quad$ ECHR Article 8.

62 OECD 'Guidelines on the Protection of Privacy and Transborder Flows of Personal Data' (1980). Retrieved 18 October 2019, http://www.oecd.org/sti/ieconomy/oecdguidelinesontheprotectionofprivacyandtransborderflowsofpersonaldata.htm. 
were first issued, the OECD had 24 members. Consistent with OECD's mission, the primary aim of the guidelines was not to curb transborder flow of data. Workable principles for data protection was a means to lessen the concerns involved. While the first bullet point of the recommendation was about taking protection of privacy into account in domestic legislation, the second bullet point read 'that Member countries endeavour to remove or avoid creating, in the name of privacy protection, unjustified obstacles to transborder flows of personal data.63

One year later, in $1981, \mathrm{CoE}$ issued a convention on personal data protection. ${ }^{64}$ The terminology and basic principles were largely in line with the OECD guidelines. The objective of the convention was to a larger degree aimed at transparency and controllability of automatic processing of data. The convention is binding upon those States which have ratified it.

Both the OECD guidelines and the CoE convention have had a major influence on development of data protection laws internationally. From an archivist point of view, the conditions for collecting and using personal data, in accordance with these principles, are unproblematic. However, the data subjects' right to challenge and to either rectify or erase erroneous data or data processed without sufficient justification, is a bit more at odds with the archival ethos. ${ }^{65}$ A quality characteristic of an archives is the authenticity of the records, which entails preserving what was purported, even if it proves wrong. Data protection quality principles tend more to emphasise correspondence between data and reality, at any time the data is retrieved.

A more severe concern, from the archivist point of view, is the principle of storage limitation. The OECD guidelines did not address storage limitation directly. The CoE convention introduced a principle of storage limitation expressed this way: '[Personal data undergoing automatic processing shall be:] preserved in a form which permits identification of the data subjects for no longer than is required for the purpose for which those data are stored' ${ }^{66}$ An obligation to delete personal data in due time, according to general provisions or according to conditions laid down in specific permits issued by authorities,

\footnotetext{
63 Ibid.

64 CoE, 'Convention for the Protection of Individuals with regard to Automatic Processing of Personal Data' (1981). Retrieved 18 October 2019, https://www.coe.int/en/web/ conventions/full-list/-/conventions/treaty/108.

65 Ibid, Article 8 (b and c); OECD Guidelines, supra note 62, para 13(d).

66 Ibid, Article $5(\mathrm{e})$.
} 
has existed both in some national laws, ${ }^{67}$ and in the former EU data protection directive. ${ }^{68}$

The principle of storage limitation has a strong position in EU data protection legislation, GDPR. Its general rule on storage limitation is almost identical to the way this principle is formulated in the CoE convention. ${ }^{69}$ However, the principle of storage limitation is not absolute. According to the 1995 directive, further processing of data for historical, statistical or scientific purposes was considered legitimate. ${ }^{70}$ The GDPR has added another legitimate purpose for further processing, 'archiving purposes in the public interest'. Further processing for these purposes needs to be in accordance with requirements for safeguarding measures in article 89(1), which leaves a margin of discretion to the Member States, while the GDPR otherwise imposes a high degree of harmonisation. ${ }^{11}$

Some conditions relating to archiving purposes are set out in recitals to the GDPR. It is apparent from the recital that archiving purposes applies to institutions with a legal obligation to manage archives according to professional standards. ${ }^{72}$ This recital also advocates use of personal data for archival purposes in ways that are specifically relevant for fighting impunity: 'Member States should also be authorised to provide for the further processing of personal data for archiving purposes, for example with a view to providing specific information related to the political behaviour under former totalitarian state regimes, genocide, crimes against humanity, in particular the Holocaust, or war crimes. ${ }^{73}$

Unfortunately, the relationship between archival law and data protection law remains an uneasy one. Data protection law in the EU concedes to legitimate needs for archiving, and it strikes a balance which is nothing much to fault about. Still, there can be a perceived imbalance in the basic arrangement, to the disadvantage of the archival community, because data protection law casts fundamental positive archival concepts such as appraisal and authenticity as exceptions to the principle of storage limitation and the right to rectification. The effects of a stronger harmonisation of data protection law on archival

67 e.g. in Norway, 'The Personal Data Registers Act' of 9June 1978 no. 48 (superseded in 200o).

68 EP and Council Directive of 24 October 1995 on the protection of individuals with regard to the processing of personal data and on the free movement of such data, 95/46/EC, OJ L $1995^{281 / 31}$ (repealed).

69 Regulation (EU) 2016/679, supra note 6o, Article 5(1)(e) first sentence.

70 Directive 95/46/EC, supra note 68, Article 6(1)(b).

71 Regulation (EU) 2016/679, supra note 6o, Article 5(1)(e) second sentence.

72 Ibid, recital 158 , second sentence.

73 Ibid, recital 158 , third sentence. 
laws are uncertain. As there is no common EU law on archives, national archival considerations could be relegated into lower visibility. On the other hand, it is also possible that shared problems and experiences could lead to shared reasoning and discernment, contributing a small step towards increased harmonisation of the archival field.

\subsection{Reuse of Public Sector Information in The European Union}

A special instance of harmonising endeavour that is unique to the EU is the directive on reuse of public sector information, abbreviated the PSI directive. The most recent version is Directive 2019/1024, which has also included 'Open Data' in its title. ${ }^{74}$ The directive, originally approved in 2003 , did not apply to documents held by cultural establishments, such as archives. ${ }^{75}$ The directive was amended in 2013, both to include more public institutions, and to clarify the obligation to make any existing data format accessible for reuse. Archival institutions were included in the scope of the directive through this amendment, along with libraries and museums. ${ }^{76}$ Further changes in the new 2019 directive includes provisions for direct access to data sources, and obligations to make data available for broader categories of bodies governed by public law, it is no longer limited to public sector bodies in the traditional sense.

The PSI directive sets forth an obligation for Member States to enact laws requiring public administration bodies to make information available for reuse, for instance to enable private companies to develop profitable services in the digital market, by making use of public information. The directive does not lift restrictions on the use of data laid down in law, such as secrecy obligations. Decisions on whether specific information can be made available or not will therefore mainly be the same as with traditional access requests to the archival institutions. The difference is in the methods, formats, and infrastructure requirements. The obligation to make digital, public information from archives accessible for reuse adds to the common expectations on archival institutions across the EU. Apart from that, it is hard to see if it implies any high degree of harmonisation.

74 Directive (EU) 2019/1024 of the European Parliament and of the Council of 20 June 2019 on open data and the re-use of public sector information, OJ $2019 \mathrm{~L} \mathrm{172/56.}$

75 EP and Council Directive of 17 November 2003 on the re-use of public sector information, 2003/98/EC, OJ L 2003 345/90, Article 1(2)(f) [original text].

76 EP and Council Directive of 26 June 2013 amending Directive 2003/98/EC on the reuse of public sector information Text with EEA relevance, 2013/37/EU, OJ L 2013 175/1, Article 1(2)(f). 


\subsection{Intellectual Property in the Archives}

Intellectual property rights have a long history of internationalisation, with multilateral conventions dating back to the 19th century. An archive is rarely conceived as intellectual property in its entirety. A more frequent, and relevant, situation is that the archive may contain different works associated with different rightsholders. Intellectual property rights generally restrict the use of specific items in an archive to what the rightsholder allows.

International treaties on intellectual property acknowledge the need for national legislation on exceptions and limitations, due to the diversity of culture and market conditions in different countries. However, there are also some dilemmas in enabling very broad categories of possible exceptions. The World Intellectual Property Organisation (WIPO) has put forward suggested convention texts for exceptions for libraries and archives, in order to direct the nature of such national exceptions. The wiro body Standing Committee for Copyright and Related Rights has made efforts to codify exceptions. The objective is to enact codified exceptions into some form of international legal instrument. The suggested exceptions and limitations are mostly relevant to libraries. Only a few of the topics in the suggested text will also be directly relevant to archives. Topics that are particularly relevant to archives are preservation and safeguarding materials, and dissemination of orphan or otherwise inaccessible works. ${ }^{77}$

In the EU, these same topics have been harmonised through different directives in the field of intellectual property rights. Preservation is part of the exceptions for non-commercial reproduction in directive 2001/29/EC. The general rule is that 'Member States shall provide for the exclusive right to authorise or prohibit ... reproduction. ${ }^{78}$ The Member States can make exceptions or limitations to this general rule in some cases, including reproductions made by archives which are not for economic advantage, and for preservation of recordings of exceptional documentary character. ${ }^{79}$ In 2019, this directive has been

77 WiPo Standing Committee on Copyright and Related Rights, 'Consolidation of proposed texts contained in document SCCR/26/3' (2014). Retrieved 18 October 2019, http://www .wipo.int/edocs/mdocs/copyright/en/sccr_29/sccr_29_4.pdf. Note: The document title refers to a document issued in 2013, named 'Working document containing comments on and textual suggestions towards an appropriate international legal instrument (in whatever form) on exceptions and limitations for libraries and archives.

78 EP and Council Directive of 22 May 2001 on the harmonisation of certain aspects of copyright and related rights in the information society, 2001/29/EC, OJ L 2001 167/10, Article 2. Ibid, Articles 5(2)(c) and 5(2)(d). 
amended by the directive 2019/790 on rights in the digital single market. ${ }^{80}$ This directive harmonises rights in cross-border use of works, by strengthening the rightsholders' position. It also aims at reducing legal uncertainty for cultural heritage institutions, both in strengthening their rights to preserve digital materials, and in clarifying their rights to use text and data mining to enhance usability of digital representations of cultural heritage.

Orphan works has an EU directive of its own, 2012/28/EU.81 The directive requires Member States to create a process of diligent search, to establish whether a work is an orphan work. Further, for orphan works, the Member States shall provide exceptions to the limits on reproduction and the right to make the work available to the public by certain cultural establishments, including archives. ${ }^{82}$

Thus, EU legislation on intellectual property rights, where exceptions apply to archives, already covers the topics outlined in the endeavours made by wIPO to regulate the scope of exceptions and limitations for archives and libraries.

\section{5}

\section{Discussion}

\subsection{A Note on Truth in the Archives}

An emerging internationalisation of archival law, and with it a partly harmonisation, aims to remedy quite different problems. Chapters 2 to 4 above address various issues such as preservation of archives in unstable international situations, societies' need for archives, the value of archives, and balancing between archival principles and other considerations in society. Well-hidden into these issues lie the questions of trust in archives, of whether one can assume that the records tell the truth.

A significant part of the basis for trustworthy archives is an accountable chain of custody, from the creation of the records to its present storing conditions. In addition to trust in archival custody, the routines and practices of creating and capturing records are also important for establishing the authenticity of the records. Authentic records can sometimes be inaccurate, or even deliberate lies, from their inception. Our best hope on detecting bad records in an archive is to uphold their custodial authenticity, and to scrutinise their content and context information at the time of use. Admittedly, these brief

8o Directive (EU) 2019/79o of the European Parliament and of the Council of 17 April 2019 on copyright and related rights in the Digital Single Market and amending Directives 96/9/ EC and 2001/29/EC, OJ L 2019 130/92.

81 EP and Council Directive of 25 October 2012 on certain permitted uses of orphan works (Text with EEA relevance), 2012/28/EU, OJ L 2012 299/5.

82 Ibid, Article 6. 
statements on the bases for trust in archives cut short a vast and nuanced part of archival discourse. The important line of reasoning, in this case, is that stability of the stored records is a necessary precondition for interpreting their content and assessing their relevance and trustworthiness at the time of use. Interpretations of the same records will likely vary over time, because of changes in our knowledge of the context of their creation, and changes in our perception of their content.

The relationship between historical facts and archival evidence has been discussed in both archival literature and legal literature. Records in the archives contribute fragments of what actually happened, they are not complete accounts. Quite often, establishment of rights and obligations are reliably recorded. Other circumstances, for instance an imbalance of power between two parties, can rarely be told directly from reading the records. It takes an interpretation, requiring context knowledge, and possibly a need to puzzle together other fragments. The inherent incompleteness and selective contents of archival sources means, in a metaphor coined by Verne Harris, they provide an 'enchanted sliver' of history: 'The archival record ... is a fragile thing, an enchanted thing, defined not by its connections to "reality," but by its open-ended layerings of construction and reconstruction. ${ }^{\prime} 3$

It can be useful to distinguish between factual truth and moral truth. In assessing factual truth from records, there is an emphasis on the evidential strength behind what the records state about the factual circumstances. A moral truth is not antithetical to a factual truth. It is not to be understood as 'necessarily not factual', but it may be an outcome interpreted from the wider context of power structures, administrative practices or cultural conditions. In a legal context, an important question is to what extent archival records are useful, trustworthy, and admissible, in a legal process. In an article about the role of the Khmer Rouge archives in Cambodia's recovery, the conflict between 'archival truth', based in the authenticity of the documents, and 'legal truth', based in admissibility of a broader range of evidence, such as documents, memories and witnesses, is thoroughly examined. ${ }^{84}$ An important finding was that the archives to a large extent succeeded in establishing truth about Khmer Rouge, and maybe more importantly, to contribute to a more coherent collective memory of the past. On the other hand, as evidence of 'legal truth' in the process, the archival evidence was still limited in its ability to contribute to justice.

83 V. Harris, "The Archival Sliver: Power, Memory and Archives in South Africa", Archival Science 2(1) (2002) 63-86.

84 M. Caswell "Khmer Rouge archives: accountability, truth, and memory in Cambodia", Archival Science 10(1) (2010) 25-44. 
Archival records are fixed traces of events and transactions. For those who demand access to archives created by an oppressive regime, exercising a right to know the truth, the archival records provide a starting point for challenging the regime's decisions and actions. Those who succeed in getting access to any relevant information, will likely benefit from a high degree of custodial authenticity of the records. For data subjects who are rightly concerned about the correctness of information pertaining to themselves, the incorrect representation of reality can be a strain. An archival ethos of maintaining authenticity will at best allow supplemental information to rectify the erroneous data. Archival records are not capable of upholding every aspect of truth at the same time.

\subsection{The Strength of Weak Harmonisation}

Archives and archival laws are seeing a wide range of influences from different fields. International developments in some fields, and harmonisation of laws in others, amount to a conglomeration of inputs to archival laws both globally and regionally. However, very few of these inputs to archival laws are based on strongly harmonised law in an adjacent field; data protection law is a notable exception. In some fields, endeavours to adopt binding multilateral rules are hanging, or have not succeeded. In other fields, there has not been a great desire to achieve binding rules. There are few formal obligations to implement common global or regional provisions into national legislation pertaining to archival institutions or archival collections. Most of the inputs to archival laws constitute weak modes of harmonisation. Still, they pull in a common direction, towards a more uniform apprehension of what archival laws ought to be.

The heading of this subsection borrows a paradoxical pun from the title of a classic sociological text, 'The strength of weak ties'. ${ }^{85}$ The paradox explained in the conclusion of the article is that strong ties between people lead to local cohesion and belonging, but also to an overall fragmentation. Weak ties are where opportunities arise, and where the integration into communities happens. ${ }^{86} \mathrm{~A}$ similar notion of a paradox between strong and weak modes of harmonisation can be useful in discussing internationalisation and harmonisation of archival law.

Harmonisation with an intention to achieve similarity of rules in archival laws was an objective of the UNESCO model law in $1972 .{ }^{87}$ This approach builds

\footnotetext{
85 M. Granovetter, "The Strength of Weak Ties", American Journal of Sociology 78(6) (1973) 1360-1380.

86 Ibid, p. 1378.

87 S. Carbone and R. Guêze, supra note 15.
} 
on a legacy of what pre-existing archival laws already cover, and on the needs for legislation, as the archival profession perceives it. An advantage is that it communicates a baseline, to help measure and compare specific archival laws against a standard. A possible problem of imposing similarity of rules in such a delimited area is a danger that it may affirm a segregation of archival law, rendering it immune to inputs emanating from adjacent fields of law. Fragments of legislation pertaining to archives would still exist, and keep evolving, outside a prospective harmonised archival law. Attempts to integrate everything archives-related into archival laws, in ever evolving legal surroundings, could become staggering. On the other hand, the impact of harmonisation could decline if it leaves large numbers of rules that are important to the archives out of archival laws.

As indicated, weak harmonisation is not necessarily a lack of harmonisation. It might better be conceived of as dispersed harmonisation efforts, aiming more at a general direction than at enforceable common rules. An approach could be to include provisions of archival legal purposes in other laws. An example would be the EU 'eIDAS' regulation on electronic IDs and signatures, comprising provisions for trust services securing long-term preservation of cryptographic digital signatures. ${ }^{88}$

A weak harmonisation approach, which is where archival law stands for the time being, it is fair to say, keep archival laws open to influences from adjacent fields. Inputs from various international and regional legal developments will not be cut off from the domain of archival law by way of a fixed scope of harmonisation that sets a high bar for including new elements.

The scope of archival laws can remain more open textured under a weak harmonisation approach. On the other hand, the conception of what archival law comprises remains informal and diverse. International legal developments, such as protection for cultural heritage at risk or fulfilling a right to know the truth, presupposes archives that meet certain professional standards. There is a dilemma between the needs for a fixed scope of archival law which could be better safeguarded by stronger modes of harmonisation, and the need to be flexible to developments in other fields which is probably best taken care of by weak harmonisation.

88 Regulation (EU) No 910/2014 of the European Parliament and of the Council of 23 July 2014 on electronic identification and trust services for electronic transactions in the internal market and repealing Directive 1999/93/EC OJ L 2014 278/73, Article 34. 
Archival laws are enacted and enforced as national laws. The need for managing archives, and to make sure the archives are trustworthy and accessible, has been and still is essentially a concern for each country. Nevertheless, laws pertaining to a professional field is also an integral part of the professional standards and of interest to the professional community. An interest in commonalities of archival laws is a natural consequence of an internationalisation of the archival profession. Professionalism and standardisation have been an impetus for proliferation of knowledge about different national archival laws, and for modest attempts of harmonising laws according to a professional outlook on best practices.

Later developments, which are still evolving, bring diverse inputs from international and regional fields of law into national law pertaining to archives. So far, these inputs do not entail binding obligation to enact specific provisions into national archival laws. The degree of actual harmonisation, by way of rule similarity or supranational enforceability of archival law, is by no means extensive. However, different fields of law, regionally and globally, are increasingly relying on trustworthy and accessible archives. Some sort of increased harmonisation of archival law could be an answer to these emerging needs. Common binding rules on archives may be tempting, but it also involves a risk of locking down the scope of archival law, thus making it less susceptible to inputs from adjacent fields of law.

The best arguments to support strong modes of harmonisation, aiming at rule similarity, akin to the model law efforts referenced in section 2.3, is probably an increased visibility of archival law in legal discourse. Strong harmonisation could provide a useful pulpit for advocating professional stewardship as a necessary precondition for keeping records accessible and reliable over time and through technological changes. Weaker harmonisation, which would entail archival provisions being more dispersed into other laws, subject to varying degrees of harmonisations on their own terms, will likely make it more difficult to be heard as a profession. Even taking the risks and the difficulties of bringing archival considerations and needs for legal provisions into 'opponent's field' of legislations serving other primary purposes, the conclusion of this paper is that weak harmonisation is the more expedient route. This is also where matters stand at present, as diverse sets of inputs to archival law forming a structure of weak harmonisations. Both lawmakers and the archival profession will have to be sensitive to different legal and societal needs involving archives, and to keep an eye on the overall cohesion of archival laws, and on what adjacent fields of law regionally and internationally need for and from the archives. 